Mills, Anne. "The Health Systems of Low and Middle-Income Countries." In Oxford Bibliographies in Public Health. Ed. David McQueen. New York: Oxford University Press 2020.

[Oxford Bibliographies can be accessed at https://www.oxfordbibliographies.com/ by subscribers]

Introduction

General Overviews

Textbooks

Conceptualising and analysing health systems

Governance and Regulation

Financing

Resource Allocation

Health Services Provision

The Private Sector

Journals

Data Sources

Toolkits For Health Systems Assessment

Other Online Resources And Websites

\title{
Introduction
}

'Health system' is a term generally considered to be relatively recent. It is defined as all organizations, institutions, and resources that produce actions whose primary purpose is to improve health, whether these be targeted at individuals (such as health care delivery) or populations (such as public health measures). Health care and public health institutions have a long history, but the notion of an organised 'health system' is a relatively recent development (dating from the mid twentieth century). In low and middle-income countries, western medicine was often introduced by former colonial authorities through the construction of public hospitals, health centres and training schools, with church authorities also making a major contribution. As in high income countries, there was a gradual process over the later part of the twentieth century to construct an organised and coordinated national health system. However, health systems only became a key focus of international attention in the late 1990s, when it became apparent that achieving the health-related Millennium Development Goals (eg reduction of child and maternal mortality, control of HIV, TB and malaria) was threatened less by the availability of technical solutions and more by the ability of health systems to put them into practice. More recently, the Ebola epidemic in West Africa highlighted the critical importance of health systems in ensuring health security. In response to the increased awareness of the role of health systems, significant attention has been paid to defining the health system and its goals, categorising its elements, assessing problems and testing solutions, and seeking to identify the relationship between different health system configurations and overall performance. Over time specific issues within the general area of health systems have received 
special attention, including achieving universal health coverage (where the whole population of a country has access to health care and protection against its costs), the role of primary health care, the relative merits of different ways of financing a health system, the relative roles of public and private health sectors, and the appropriate mix of different types of health worker. Many disciplines can contribute to improved understanding of health systems, including economics, sociology, anthropology, history, political science, and management science. Until recently, the discipline of economics has tended to dominate the study of health systems. However, with the emergence of health policy and systems research as an important area of study, other disciplines have been making growing contributions, especially political science and the behavioural sciences concerned with the behaviour of both individuals and organizations.

\section{General Overviews}

This section includes publications which either provide overviews of the development of health systems as a field of study or which represent landmark publications which shaped knowledge and opinion. The historical antecedents of the concept of a health system is explored in Gorsky 2016, who argues that it was the construct of leading social democratic thinkers in the mid twentieth century, and identifies the tension, which is more generally apparent in the literature, between technical analyses and value-based approaches. Bennett et al 2018 provide a historical analysis of the evolution of the field of health policy and systems research (HPSR) since 1996, listing key publications and events. Initially, the development of the literature focused on technical analysis. The seminal 1993 World Development Report (World Bank 1993), employed burden of disease and costeffectiveness analysis to identify limited packages of public health and essential clinical interventions which should be top priorities for government finance, and more broadly analysed health systems and their problems and proposed solutions. The equally famous - or infamous - World Health Report 2000 (WHO 2000), defined the goals of a health system and developed methods and metrics which were used to rank country health system performance. Subsequent World Health Reports have explored specific aspects of health systems, including the health workforce in WHO 2006, primary health care in WHO 2007 and financing and universal coverage in WHO 2010. The World Bank continued its focus on what governments should do by addressing the failure of public services to meet the needs of the poor in World Bank 2004. Comparative country studies are adding depth to these global overviews of how health systems function and can be improved. For example, Balabanova et al 2011 sought to understand how five countries have made progress towards the goal of health systems at low cost and the role of the health system in their achievements. Conventional conceptual frameworks for analysing health systems are critiqued by Gilson 2012 using an 'institutional' lens and drawing on a range of organizational and policy implementation theories.

Balabanova, D., McKee, M., and Mills, A. Eds. 2011. 'Good health at low cost' 25 years on What makes a successful health system? London: London School of Hygiene \& Tropical Medicine. 
In 1985 the Rockefeller Foundation published a seminal report: 'Good health at low cost', highlighting and seeking to explain achievements of China, Costa Rica, Cuba, the Indian state of Kerala and Sri Lanka. Twenty-five years later the Foundation commissioned research to revisit these countries and examine in depth five more countries. The book demonstrates how rich historical analysis can shed light on the contribution of health systems to health improvement.

Bennett, S., Frenk, J., and Mills, A. 2018. The evolution of the field of Health Policy and Systems Research and outstanding challenges. Health Research Policy and Systems 16:43.

*[https://doi.org/10.1186/s12961-018-0317-x]*

Recognition of the importance of health systems has been accompanied by efforts to establish health policy and systems research as a field of enquiry which can support countries to improve health system performance. This paper identifies challenges and how they have been addressed, concluding that there remain issues such as those of strengthening research capacity and bringing together the rather separate bodies of knowledge in high versus low and middle-income countries.

Gilson, L. 2012. Health systems and institutions. In Smith, R. D. and Hanson, K. Eds. 2012. Health systems in low and middle-income countries: an economic and policy perspective. Oxford: Oxford University Press.

Highlights the dominance of a mechanical perspective of organizational functioning in conventional health system frameworks, and a command and control approach to health systems strengthening. Proposes two alternative approaches to supporting change within health systems: soft systems methodology and strengthening trust-based relationships.

Gorsky, M. 2016. *The Idea of a health system: International Health Organizations and the genesis of comparative health systems research, 1891-1969 [http://researchonline.Ishtm.ac.uk/3928362/].* China Journal of the Social History of Medicine and Health 1. 1: 28-57.

Applies historical research methods to understand how the concept of a health system developed, identifying its early use in the 1930s and 1940s, and escalating use in the late 1960s and 1970s. Suggests that the current aspiration to provide robust comparative data for policy-makers ignores the centrality of issues of political philosophy and ideology in debates on health system design and performance. 


\section{World Bank. 1993. World Development Report 1993 Investing in Health. New York: Oxford University Press.}

Still stands as a model of applying rigorous economic and epidemiological thinking to identify government policies for improving health in low and middle-income countries. Many aspects of its recommendations were disputed, but it brought together evidence and analysis to address questions that persist today: eg the relative roles of government and market, and priorities in the provision of public health and clinical services.

World Bank. 2003. World Development Report 2004 Making services work for poor people. New York: Oxford University Press.

Adds intellectual depth to the 1993 World Development Report by focusing on common deficiencies across public services which help explain why they fail poor people - in access, quality and quality. Takes institutional perspective and argues that improvements require strengthened accountability between poor people and providers, poor people and policy makers, and policy makers and providers. Calls for donors to reinforce these accountability relationships, not undermine them.

\section{World Health Organization. 2000. The World Health Report 2000 Health systems: Improving performance. Geneva: World Health Organization.}

The first major analysis by the WHO on health systems and their performance. Proposes 3 goals for health systems - better health, fair financing, and responsiveness; and four functions that health systems need to carry out - delivering services, financing, creating resources and stewardship. Assesses health systems performance according to this framework. The framework has been widely used, though the ranking of country performance proved highly controversial and has not been repeated.

\section{World Health Organization. 2006. The World Health Report 2006: Working together for health. Geneva: World Health Organization.}

First major analysis of the human resources crisis especially affecting health systems of low-income countries and proving one of the most intractable challenges to address. Focuses on all stages of health workers' careers from entry to health training, job recruitment and retirement. Includes discussion of the global 'brain drain' where rich countries recruit from overseas. Recognises that solutions are not straightforward and there is no consensus on action. 
World Health Organization. 2007. The World Health Report 2007: Primary health care. Now more than ever. Geneva: World Health Organization.

Continues the series of World Health Reports addressing various dimensions of health systems. Issued to coincide with the $30^{\text {th }}$ anniversary of the famous Declaration of Alma Ata and makes the case for a focus on primary health care within health systems strengthening. Proposes four sets of reforms: universal coverage reforms, service delivery reforms, leadership reforms and public policy reforms.

World Health Organization. 2010. The World Health Report: Health systems financing. The path to universal coverage. Geneva: World Health Organization.

Directly addresses universal coverage, but concentrates on the financing function: raising money, pooling funds, and paying providers. Useful review of issues and how to address them. Chapter titles of 'More money for health' and 'More health for the money' mean balanced coverage on how to increase the volume of funds versus how to use those funds efficiently.

\section{Textbooks}

The subject of health systems has only recently emerged as a field of enquiry and educational programmes and hence textbooks are still few. Merson, Black and Mills 2018 is a global health textbook designed for graduate programmes in global and public health. It contains a number of chapters relevant to health systems. Smith and Hanson 2012 provide comprehensive coverage of the health systems of low- and middle-income countries from a political economy lens, and Birn, Pillay and Holtz 2017 apply the same lens to global health more broadly. Peters, El-Saharty, Siadat et al 2009 provide useful systematic reviews of the literature related to strengthening health services delivery. Along with the development of health systems as a subject of enquiry has come the development of methods to study them: Gilson 2012 is an invaluable guide not just to methods but also to the field in general.

Birn, A-E., Pillay, Y., and Holtz, T. H. 2017. Textbook of Global Health. 4th ed. New York: Oxford University Press.

Employs a political economy framework in the book and there is material throughout relevant to health systems. Specific chapters cover 'Understanding and Organizing Health Care Systems' and 'Health Economics and the Politics of Health Financing'.

Gilson, L. Ed. 2012. Health policy and systems research: a methodology reader. Geneva: World Health Organization. 
A great starting point for anyone wishing to learn how to do health policy and systems research - or even just wanting to know how to critically appraise the literature. Has valuable preliminary sections on health systems and on steps in research, as well as papers grouped by research strategy with introductory sections providing an overview of the strategy, an overview of selected papers, and a brief summary of each paper.

\section{Merson, M., Black, R., and Mills, A. Eds. 2018. Global Public Health: Diseases, Programmes,} Systems and Policies. $4^{\text {th }}$ edition. Burlington MA: Jones and Bartlett Learning.

A comprehensive graduate-level text with substantial chapters covering the main diseases and programmes. Health systems relevant material includes not just a chapter on health systems, but also chapters on public health infrastructure, management and planning, pharmaceuticals, health and the economy, and trade and health.

Peters D., El-Saharty S., Siadat B., et al Eds. 2009. Improving Health Service Delivery in Developing Countries: From Evidence to Action. Directions in Development; Human Development; Washington DC: World Bank. *[https://openknowledge.worldbank.org/handle/10986/12335]*

Pulls together available evidence through comprehensive and systematic reviews of the literature concerning strategies to improve health services delivery in low- and middle-income countries. Also describes how such strategies can produce gains for the poor.

Smith, R. D. and Hanson, K. Eds. 2012. Health systems in low and middle-income countries: an economic and policy perspective. Oxford: Oxford University Press.

Devotes the whole book to the health systems of low and middle income countries, addressing them through the perspective provided by economics, political sciences and policy analysis. Four sections address in turn the conceptualisation of a health system, the domestic health sector, international and cross-sectoral influences on health care and health, and next steps for health system strengthening and analysis.

\section{Conceptualising and analysing health systems}

The performance of health systems cannot be addressed without understanding their goals, the elements that make up a health system, and the combination of elements and forces that define different types of health system. Murray and Frenk 2000 provide a framework for assessing the performance of health systems based on identification of 3 fundamental goals. This was the basis for 
WHO's ranking of health system performance referred to above in section 2. These goals relate to health outcomes, financial protection, and responsiveness to patient expectations. The most widely cited source on elements of a health system is WHO 2007 introducing what are known as the 'building blocks'. These and similar frameworks can be criticised for focusing more on health systems 'hardware' than 'software' - the latter being the values of all the actors involved in health systems and the ways in which dynamic interactions amongst a huge variety of stakeholders, including the general public, influence health system functioning. For example, health systems can be conceived of as social institutions (Gilson 2003), and van Olmen et al 2012 propose a framework for description and analysis of health systems dynamics, consisting of ten elements focusing on system interactions. In addition to serving health and financial protection goals, health systems can be seen as a demonstration of social solidarity (Kruk et al 2010) and analysed from a human rights perspective (Backman et al 2008). Gilson et al 2017 demonstrate how the concept of 'everyday resilience' can shed light on the important role of managers and leaders. Key in health system performance is how the different elements relate to each other and what are the financial and other incentives, as well as underlying political, social, and economic institutions, which influence individual, organizational and health system behaviour. Given the huge variety in country health systems, categorisation of different types of health system is needed to make progress in understanding performance, though the application of systems theory and systems thinking has been helpful in warning of the complexity of health systems (De Savigny and Adam 2009). Health system typologies are still at an early stage of development with the most helpful contributions being from OECD (eg OECD 2011) though they are most relevant to the more developed health systems of middle and high-income countries and primarily reflect economic dimensions.

Backman, G., Hunt, P., Khosla, R., et al. 2008. Health systems and the right to health: An assessment of 194 countries. Lancet 372.9655: 2047-2085 doi: 10.1016/S0140-6736(08)61781-X

This paper applies the perspective of the right to health to examine health system functioning, arguing that the right to health is central to the creation of equitable health systems. 72 indicators are identified to reflect right-to-health features of health systems, and used to assess 199 countries to identify where health systems need to be improved to better realise the right to health.

\section{de Savigny, D. and Adam, T. Eds. 2009. * Systems thinking for health systems strengthening [http://whqlibdoc.who.int/publications/2009/9789241563895_eng.pdf]*. Geneva: Alliance for Health Policy and Systems Research.}

Health systems are prime examples of complex systems. This publication explores how systems thinking can help in health systems strengthening. It covers what systems thinking is, provides 
guidance and illustrations in how to apply a systems perspective, and identifies challenges and opportunities.

Gilson, L. 2003. Trust and the development of health care as a social institution. Social Science \& Medicine, 56.7:1453-1468

Argues that relationships, behaviours and the factors that influence them are central to health systems. Trust has a key role in facilitating collective action, namely co-operation among people to achieve common goals, and offers an alternative approach to the economic individualism that has driven public policy analysis in recent decades. The paper explores the meaning, bases and outcomes of trust, and its relevance to health systems.

Gilson, L., Barasa, E., Nxumalo, N., et al. 2017. Everyday resilience in district health systems: emerging insights from the front lines in Kenya and South Africa. BMJ Glob Health 2:e000224. DOI: 10.1136/bmjgh-2016-000224

The Ebola epidemic in West Africa encouraged a focus on how health systems can be resilient in the face of such threats. This paper coins the term 'everyday resilience', to shed light on how routine, multiple challenges affect health care services, drawing on long-term, primarily qualitative research conducted in three different district health system settings in Kenya and South Africa. Features of management and leadership are identified that support the resilience of district health systems.

Kruk, M. E., Freedman, L. P., Anglin, G. A., and Waldman, R. J. 2010. Rebuilding health systems to improve health and promote state building in post-conflict countries: A theoretical framework and research agenda. Social Science \& Medicine 70.1: 89-97 DOI:

10.1016/j.socscimed.2009.09.042

European health systems are often seen as the embodiment of principles of social solidarity. This paper draws on the literature about health systems as social and political institutions to argue that the rebuilding of a health system following prolonged conflict can similarly demonstrate a state's commitment to equity and strengthening government accountability to citizens.

Murray C.J.L. and Frenk J. 2000. A framework for assessing the performance of health systems. Bulletin of World Health Organization 78.6:717-731.

A detailed justification and explanation of the framework for assessing health system performance that was applied in the World Health Report 2000 (see WHO 2000 under *General overviews*). Argues that the implementation of this framework will help discussion of health system performance 
to focus on empirical evidence rather than ideological argument, and with improved data will make it possible to examine questions such as whether competition among purchasers or providers enhances responsiveness.

Organization for Economic Cooperation and Development (OECD). 2011. A new look at OECD health care systems: Typology, efficiency and policies. Part II Chapter 6 pp. 221-237 In Economic policy reforms 2011. Going for growth. Paris: OECD.

Examines the health systems of OECD countries. Identifies six groups of countries each sharing a broadly similar health care system. The categorisation is based on degree of reliance on market mechanisms and regulations to steer demand and supply, including the importance of private providers, degree of patient choice of provider, extent of health insurance markets, and application of gate-keeping arrangements. Concludes that no single type of health system systematically outperforms others.

Van Olmen, J., Criel, B., Bhojani, B., et al. 2012. The health system dynamics framework: the introduction of an analytical model for health system analysis and its application to two casestudies. Health, Culture and Society 2.1 DOI 10.5195/hcs.2012.71

Criticises the limited capacity of existing health system frameworks to analyse the interactions and balance between different elements of a health system. Key omissions are the role of values in influencing people's behaviour and choices, and the strong influence and interactions of a large variety of different stakeholder groups. The paper proposes a framework for description and analysis of health system dynamics, involving ten elements which focus on system interactions.

World Health Organization (WHO). 2007. Everybody's business: Strengthening health systems to improve health outcomes: WHO's framework for action. Geneva: WHO.

Justifies and explains the health system 'building blocks' now very widely used to analyse health systems and identify strengthening needs (and criticised by those who focus more on the people, relationships and values aspects of health systems). They are based on the functions defined in World Health Report 2000 (see WHO 2000 under *General overviews*) and are service delivery; health workforce; information; medical products, vaccines and technologies; financing; and leadership and governance (stewardship).

\section{Governance and Regulation}

Governance of health systems concerns the set of rules guiding the roles and responsibilities of political, economic and institutional processes in order to achieve health system objectives. 
Brinkerhoff and Bossert 2014 stress that governance goes well beyond the task of a Ministry of Health, to encompass the multiplicity of actors in health systems. 'Political will' is often called for to achieve major health system improvements, but this phrase disguises the major challenges in improving health system governance in countries which by definition have poorly developed systems of governance and accountability. Siddiqi et al 2009 provide a framework for assessing health governance at the national and subnational level which has been applied in Eastern Mediterranean countries. Weak governance is a major problem for health service delivery in fragile states, and Berry and Igboemeka 2004 explore its implications in three fragile states. 'Accountability' provides a related lens which can be helpful in exploring failures in governance where these relate to weak mechanisms of accountability. Brinkerhoff 2004 defines accountability and provides an analytical framework for mapping accountability; see also World Bank 2004 chapter 3 under *General Overviews* where accountability failings are used to explain failures in service provision for the poor. Chapter 4 in Peters, El-Saharty and Siadat 2009 under *Textbooks* reviews community empowerment strategies. Empirical exploration of the day-to-day micro practices of health system governance, including accountability processes, can be found in Nxumalo et al 2018. Two major topics within the general area of governance are the role of government and regulation. The role that government should play in various aspects of health systems continues to be the subject of much debate and controversy. Economic theory provides a framework, covered in any health economics textbook, though a short and succinct explanation is provided on pp5-6 in the World Development Report 1993 (see World Bank 1993 in *General Overviews*). The reality is that governments play a much greater role in health systems that can be justified by traditional economic theory, with their interventions encompassing regulation, financing, purchasing, and provision. Financing, purchasing and provision are considered in *Financing*, *Purchasing* and *Provision*. Regulation is one of the key functions within governance and can encompass not just control and sanctions but also incentives. Ensor and Weinzerl (2007) explore the challenges of health system regulation in low and middle-income countries, and Doherty 2015 and Sheikh et al 2013 provide country evidence, from East and Southern Africa for the former, and two states in India for the latter.

\section{Berry, C., and Igboemeka, A. 2004. * Service provision in difficult environments: Issues arising from DFID support to health sector interventions in Burma, Afghanistan, and Nepal [http://gsdrc.org/docs/open/sd27.pdf]*. London: Department for International Development.}

Weak governance presents especial challenges in fragile and post conflict states, termed here 'difficult environments', and in the context of overseas aid. This paper explores policy and operational issues that arise when a bilateral agency seeks to support service delivery in a state that is either unwilling or lacks the capacity to facilitate service delivery. Through examples in Maoist areas of Nepal, Afghanistan and Burma, it identifies five key issues for policy makers to consider. 
Brinkerhoff, D.W. 2004. Accountability and health systems: toward conceptual clarity and policy relevance. Health Policy Plan. 19.6:371-9. *[DOI: 10.1093/heapol/czh052]*

Seminal paper on the meaning of accountability in health systems, distinguishing three types; financial, performance and political/democratic. The purposes of accountability are described and its link to health system performance identified.

Brinkerhoff, D.W. and Bossert T.J. 2014. Health governance: principal-agent linkages and health system strengthening Health Policy Plan, 29.6:685-693 *[DOI: 10.1093/heapol/czs132]*

Acknowledges the increased recognition of governance as a critical influence on health system performance, but argues governance remains poorly understood. Introduces the principal-agent framework to help understand the behaviours of health system actors and diagnose performance problems. Draws on three country case studies to argue for the importance of moving from identifying problems to developing practical guidance on effective interventions.

Doherty, J. E. 2015. Regulating the for-profit private health sector: Lessons from East and Southern Africa. Health Policy Plan, 30.suppl 1: i93-i102. *[DOI: 10.1093/heapol/czu111]*

Provides overview of legislation governing the private-for-profit private health sector in this region, finding that most legislation focuses on controlling entry into the market not performance in the market. Moreover, the type, volume, distribution, quality and price of health care services are not well monitored or controlled, and only a few countries have legislation specific to health insurance (as opposed to general insurance). Regulatory reform has to be carefully planned to manage the power of private sector actors to undermine efforts.

Ensor, T., and Weinzierl, S. 2007. Regulating health care in low- and middle-income countries: Broadening the policy response in resource constrained environments. Social Science \& Medicine, 65.2:355-366. *[DOI: 10.1016/j.socscimed.2007.03.021]*

A useful overview of the topic of regulating health care in low and middle-income countries based on a typology of regulatory strategies and structured literature search. Given the failures of traditional approaches to regulation, the paper explores a wider range of administrative controls and incentives that might help a market work better, such as contracting, accreditation, and providing information on service quality to individuals, community groups and the media. 
Nxumalo, N., Gilson, L., Goudge, J. et al. 2018. Accountability mechanisms and the value of relationships: experiences of front-line managers at subnational level in Kenya and South Africa. BMJ Glob Health. 3.4:e000842 DOI: 10.1136/bmjgh-2018-000842

An interesting, in depth exploration of how governance and accountability mechanisms play out at the local level, especially in the context of decentralisation. The paper highlights some of the unintended consequences of bureaucratic forms of accountability, and the key influence of interpersonal interactions on how accountability mechanisms function.

Sheikh, K., Saligram, P.S., and Hort, K. 2013. What explains regulatory failure? Analyzing the architecture of health care regulation in two Indian states. Health Policy Plan 30.1:39-55. *[DOI: 10.1093/heapol/czt095]*

Focuses on exploring and explaining the extensive gap between formal regulations and implementation in practice. Reasons for regulatory gaps included human resource constraints of regulators, problematic organizational relationships and capture of regulatory processes by private interests. These failures are linked to poor governance, which has to be addressed if regulatory performance is to be improved.

Siddiqi, S., Masud, T., Nishtar, S.et al. 2008. Framework for assessing governance of the health system in developing countries: gateway to good governance Health Policy. 90.1:13-25. *[DOI: 10.1016/j.healthpol.2008.08.005]*

Develops a framework for assessing health system governance based on identifying key issues and reviewing four existing frameworks. Applies the framework to diagnose weaknesses in health system governance in countries of the Eastern Mediterranean, and suggest interventions which might improve governance.

\section{Financing}

Financing sources and agents are considered here; purchasing, which is included in the financing function in the WHO building blocks categorisation (see WHO 2007 in *Conceptualising and analysing health systems*) is considered in *Resource Allocation*. The primary sources of finance for health systems are individuals and firms who either pay directly for health care or pay indirectly via taxes, and entities external to a country such as the international and bilateral aid agencies. However, the word 'source' is more often applied to the method whereby an agent mobilises or collects resources, where the agents are, for example, Ministries of Health, social insurance agencies, private insurers, and non-governmental organizations (NGOs), and the methods are various types of taxes, insurance premium payments, and direct (user) payments. Gottret and Schieber (2006) provide a 
comprehensive overview covering both sources of funds and pooling issues. Pooling, including the value of single versus multiple pools, is well addressed in Chapter 4 of Smith and Hanson 2012 in the section on *Textbooks*. There is an abundant literature on various sources of financing, especially direct payments. The classic reference on the impact of direct payments on households is Xu et al 2003 and Russell and Gilson 2006 is a good example of the many in-depth studies of households which have explored how they cope with health care costs and the policy implications. There are a number of studies of the impact of user fee removal, including Lagarde et al 2012 on Zambia and Niger, and Qin et al 2019 is a recent systematic review. Universal health coverage goals are focusing attention on domestic resource mobilisation, especially through increased tax funding for health and social health insurance. Tangcharoensathien et al 2011 identify the challenge of how best to ensure financial protection for the informal sector and Wagstaff 2010 takes a careful look at the pros and cons of social health insurance. Low income countries can be heavily dependent on donor funding which has its own set of advantages and disadvantages such as deficiencies in harmonisation and alignment with country systems (Martinez-Alvarez et al 2017). Financing and benefit incidence studies can be used to assess the equity of health finance and there is a growing body of country evidence (Asante et al 2017).

Asante, A., Price, J., Hayen, A., Jan, S., and Wiseman, V. 2016. Equity in health care financing in low-and middle-income countries: A systematic review of evidence from studies using benefit and financing incidence analyses. PLOS One 11.4 p.e0152866

The increase in the number of benefit and financing incidence studies in low and middle-income countries has made possible this systematic review which finds that health care financing benefits the rich more than the poor, but the burden of financing also falls more on the rich. Primary health care appears generally to be pro-poor, suggesting that equity could be improved by greater investment in such services and, more broadly, by reducing barriers to access to care for the poor.

Gottret P. and Schieber G. 2006. Health financing revisited. A practitioners guide. Washington D.C.: World Bank.

A useful text on health financing tools, policies, and trends, with a focus on challenges facing developing countries. Their numbers are outdated (see section *Data Sources* for websites with current data), but the analytical framework and issues are well presented. Chapter 2 and Figure 2.1 provide an overview.

Lagarde, M., Barroy, H. and Palmer, N. 2012. Assessing the effects of removing user fees in Zambia and Niger. J Health Serv Res Policy 17.1:30-36. DOI: 10.1258/jhsrp.2011.010166 
This study adds to evidence of the effects of user fee removal by looking at heterogeneity of effects within countries and over time, and at spill-over effects on groups not targeted by the policy change. Targeted groups increased their use of services but this differed widely across districts, highlighting the importance of implementation challenges and of monitoring the effects of policy reforms.

Martínez-Álvarez, M., Acharya, A., Arregoces, L. et al. 2017. Trends in the alignment and harmonization of reproductive, maternal, newborn, and child health funding, 2008-13. Health Affairs 36.11:1876-1886. DOI: 10.1377/hlthaff.2017.0364

Principles of aid effectiveness include alignment of donor financing with recipient public financial management systems, and harmonisation of donor financing to avoid fragmentation and high transactions costs. This study found reduction over time in the share of funds channelled through governments, and low overall harmonisation.

Qin V., Hone T., Millett C. et al. 2019. The impact of user charges on health outcomes in lowincome and middle-income countries: a systematic review. BMJ Global Heath *[DOI:10.1136/bmjgh-2018-001087]*

Finds that reduced user charges are associated with improved health outcomes, particularly for lower-income groups and children.

Russell, S., Gilson, L. 2006. Are health services protecting the livelihoods of the urban poor in Sri Lanka? Findings from two low-income areas of Colombo. Social Science \& Medicine 63.7: 17321744. DOI: 10.1016/j.socscimed.2006.04.017

An interesting example of research on out-of-pocket expenditure given Sri Lanka's historically strong system of free health care. Combining survey data and longitudinal case study household research enabled the identification of highly vulnerable households who struggled and became more impoverished, vulnerable households who coped to different degrees, and resilient households who invested and improved. Free health care protected against illness-induced impoverishment, but only if quality was acceptable.

Tangcharoensathien, V., Patcharanarumol, W., Ir, P. et al. 2011. Health-financing reforms in southeast Asia: challenges in achieving universal coverage. Lancet 377: 863-873*[DOI: 10.1016/S0140-6736(10)61890-9]*

Compares financing strategies used by seven countries to reduce out-of-pocket payments, pool health finance, and enable increased service use. Given the common use of targeted subsidies for 
the poor and social health insurance for formal sector employees, the key challenge in financing universal coverage is protecting the non-poor outside the formal sector. Experience with the two alternatives of contributory and tax-financed arrangements is assessed.

\section{Wagstaff, A. 2010. Social health insurance reexamined. Health Econ 19.5:503-517. * [DOI: 10.1002/hec.1492]*}

Contrasts reduction in reliance on using payroll taxes for social health insurance (SHI) in Europe with the growing enthusiasm for SHI in much of the developing world. Argues that $\mathrm{SHI}$ may not deliver good quality care at a low cost, can have substantial costs of revenue collection, fares badly in covering non - poor informal sector workers, and can have negative labour market effects.

\section{Xu, K., Evans, D., Zeramdini, R. et al. 2003 Household catastrophic expenditure: a multicountry analysis. Lancet 362:111-117. *[DOI: 10.1016/S0140-6736(03)13861-5]*}

The classic quantitative paper on the poverty-increasing effects of out-of-pocket payments for health care (termed 'catastrophic' expenditure). Based on cross-country analysis, three key preconditions for catastrophic payments were identified: the availability of health services requiring payment, low household capacity to pay, and the lack of prepayment or health insurance arrangements. Financial protection measures are critical and must accompany increased service availability which otherwise would worsen the problem.

\section{Resource Allocation}

Resource allocation, also known as purchasing, is the transfer of funding from financing agents, such as ministries of health and insurance agencies, to service providers. It is inherently a priority-setting process, whether this is done explicitly or implicitly. This transfer can occur in a hierarchical system via planning and budgeting processes, or between arm's length organizations (eg public purchasers and public providers) or organizations with different ownership (eg public purchasers and private firms), via formal agreements including contracts. In recent years there has been an emphasis on 'strategic purchasing', namely purchasing value for money services which meet the needs of a defined population, and using payment methods which provide incentives for efficiency and sometimes also equity. Figueras et al 2005 provide a comprehensive overview of purchasing, with evidence drawn from Europe though the analysis is broadly applicable. Strategic purchasing involves defining the priority package of services to be funded, and the more limited the resources, the more challenges this presents. Health technology assessment methods based on cost-effectiveness analysis form the core analytical tool, though prioritisation processes involve a much broader range of considerations than simply cost-effectiveness (Glassman et al 2017). The Disease Control Priorities project identifies priorities based on value for money, burden addressed, and 
implementation feasibility across a huge range of diseases and conditions, as well as grouping these into health system and inter-sectoral packages (Jamison et al 2017). Strategic purchasing has been easier to define than to implement, and Yip and Hanson 2009 for example identify the challenges based on experience in China. A key issue is the payment method, and 'pay for performance' - linking payment to explicit service targets - has been strongly advocated though the evidence base is still inconclusive. A Cochrane review (Witter et al 2012) concluded the evidence base was too weak to draw general conclusions, and a more recent Cochrane review for outpatient care facilities (Yuan et al 2017) concluded that pay-for-performance systems probably have only small benefits or make little or no difference. Binyaruka et al 2015 assess the effects of pay for performance at scale in Tanzania and highlight the potential risks of such schemes in reducing use of non-targeted services. Demand side payments have also been tried to elicit desired use of services, sometimes alongside supply side payments. Powell-Jackson et al 2015 studied the health effects of one of the world's largest health cash transfer programmes.

Binyaruka, P., Patouillard, E., Powell-Jackson, T., Greco, G., Maestad, O., Borghi, J. 2016. Effect of Paying for Performance on Utilisation, Quality, and User Costs of Health Services in Tanzania: A Controlled Before and After Study. PLOS One 10.8:e0135013 *[DOI: 10.1371/journal.pone.0135013]*

Examined the effect of a large-scale government pay-for-performance scheme on utilisation, quality, and user costs of health services in Tanzania. There was a significant positive effect on two out of eight targeted indicators, but use of non-targeted services reduced, highlighting the importance of scheme design and monitoring.

Figueras, J., Robinson, R., and Jakubowski, E. 2005. *Purchasing to improve health systems performance: drawing the lessons.

[http://www.euro.who.int/_data/assets/pdf_file/0004/98428/E86300.pdf?ua=1]* Pp 44-80 in Figueras, J., Ronson, R., and Jakubowski, E. Eds. Purchasing to improve health systems performance. Buckingham: Open University Press.

Outlines role of purchasing given objectives of a health system, and summarizes theoretical rationale for purchasing and the expected benefits. Discusses evidence of benefits of purchasing and draws lessons for policy makers around five central themes for improving purchasing. Concludes with reflections on the evidence and the way forward.

Glassman, A., Giedion, U., Smith, P.C. Eds. 2017.*What's in, what's out: designing benefits for universal health coverage. [https://www.cgdev.org/publication/whats-in-whats-out-designingbenefits-universal-health-coverage ]* Washington D.C.: Center for Global Development 
Argues that an explicit health benefits package - a defined list of services that will be publicly funded - is an essential element of a sustainable and effective health system. Chapters include consideration of issues such as governance, budgets, methods, political economy, and ethics relevant to consideration of what services should be included and a process that is fair, evidence-based, and sustainable over time.

Jamison, D., Alwan, A., Mock, C.N. et al. 2017. Universal health coverage and intersectoral action for health: key messages from Disease Control Priorities, $3^{\text {rd }}$ edition. Lancet 391.10125:1108-1120. *[DOI: 10.1016/S0140-6736(17)32906-9]*

A summary and overview of the huge resources and main messages of the Disease Control Project. Interventions are organised into 21 essential packages containing mix of intersectoral policies and health-sector interventions, with the latter grouped onto five platforms (population based, community level, health centre, first-level hospital, and referral hospital). An essential universal health coverage packaged is proposed with 218 interventions; a subset is proposed as a High Priority Package.

Powell Jackson, T., Mazumdar, S. and Mills, A. 2015. Financial Incentives in Health: New Evidence from India's Janani Suraksha Yojana. Journal of Health Economics. 43:154-69.*[DOI: 10.1016/j.jhealeco.2015.07.001]*

Uses difference in difference analyses to estimate the health effects of a very large demand-side incentive programme, finding that cash incentives to women were associated with increased use of maternity services. There was no strong evidence of mortality reductions, and an unanticipated effect was found in the form of increased pregnancies.

Witter, S., Fretheim, A., Kessy, F.L. and Lindahl, A.K. 2011. *Paying for performance to improve the delivery of health interventions in low- and middle-income countries [https://www.cochrane.org/CD007899/EPOC_paying-for-performance-to-improve-the-deliveryof-health-interventions-in-low-and-middle-income-countries]*

Assesses systematically the current evidence on the effects of paying for performance on the provision of health care and health outcomes in low- and middle-income countries, finding that the evidence base is too weak to draw general conclusions. Comments that performance-based funding is not a uniform intervention but a range of approaches with effects depending on issues such as design, funding level, technical support, and contextual factors. 
Yip, W. and Hanson, K. 2009. Purchasing health care in China: Experiences, Opportunities and challenges. Pp.197 - 218 in D. Chernichovsky and K. Hanson Eds. Innovations in Health System Finance in Developing and Transitional Economies (Advances in Health Economics and Health Services Research, Volume 21). Bingley UK: Emerald Group Publishing Limited.

Analyses critically how purchasing has been used strategically in China, how it might be used, and the modifications that might be needed if purchasing is to ensure that the considerably increased government funding for health care will be used efficiently and effectively.

\section{Yuan, B., He, L., Meng, Q. and Jia, L. 2017. * Payment methods for outpatient care facilities [https://www.cochrane.org/CD011153/EPOC_payment-methods-outpatient-care-facilities]*}

Systematically assesses the impact of different payment methods on the performance of outpatient care facilities, finding that pay-for-performance incentives probably lead to a slight improvement in health professionals' use of tests or treatments, particularly for chronic diseases, but may produce little or no improvement in patients' utilisation of health services or health outcomes.

\section{Health Services Provision}

Health service provision in the great majority of low and middle-income countries is characterised by diversity and fragmentation. The highly structured health systems seen in almost all high-income countries, where universal coverage systems mean coordinated financing and provision, are present only in relatively few countries. A common pattern is a publicly financed and provided set of services providing very partial coverage, other systems of finance and provision for specific population groups (eg those under social health insurance arrangements, or specific occupational schemes such as the military), privately-run health services which in poorer countries have very limited coverage but in less poor countries may be widely available, and a huge informal private sector including publiclyemployed health workers offering services for payment, unlicensed practitioners and drug sellers, and a range of types of traditional practitioner. Comprehensive information on the characteristics of health services provision in LMIC is unavailable (unlike in OECD countries - see *Data sources*), but WHO and World Bank databases (see *Data Sources*) provide a variety of indicators covering levels of expenditure, human resources inputs, pharmaceutical availability, health service delivery, and coverage of specific interventions. Some topics have received special attention, notably the role of primary health care (eg Frenk 2009), the role of hospitals (eg English et al 2006, Hensher et al 2006), service integration (eg Mayhew et al 2017), quality (Kruk et al 2018) and task-shifting to lower levels of care and to less qualified health workers including lay health workers (eg Lewin et al 2010). The role and contribution of community health workers has been much studied, with for example Schneider et al 2016 providing a scoping review of recent literature, and Kok et al 2015 identifying design factors associated with community health worker performance. Services for specific 
diseases, conditions, and populations (such as mothers and children) are covered in other entries in this bibliography. An area of considerable controversy has been the role of the private sector: see *Private sector*.

English, M., Lanata, C.F., Ngugi I. and Smith P. 2006. The District Hospital. Pp. 1211-1228 in Jamison, D., Breman, J.G., Measham, A.R. et al. Eds. Disease Control Priorities in Developing Countries. Second Edition. New York: Oxford University Press.

District hospitals play a critical role in service delivery. This chapter discusses their role and what services they should provide. Available economic information on district hospitals is summarised, and factors affecting performance discussed. Strategies for improving performance are considered.

Frenk J. 2009. Reinventing primary health care: the need for systems integration Lancet 374: $170-73 *[D O I: 10.1016 /$ S0140-6736(09)60693-0]*

Makes the case for reinventing primary health care based on developing primary care networks that are

seamlessly integrated into the rest of the health system to assure provision of high-quality services on the basis of a defined population, through proactive strategies favouring continuity of care, guaranteeing an explicit set of entitlements, and assuring universal social protection in health.

Hensher, M., Price, M. and Adomakoh, S. 2006. Referral Hospitals. Pp 1229-1243 in Jamison, D., Breman, J.G., Measham, A.R. et al. Eds. Disease Control Priorities in Developing Countries. Second Edition. New York: Oxford University Press.

A parallel chapter to the one on district hospitals in the same volume. Provides an overview of the critical features of referral hospitals in developing countries, identifies their challenges, and considers the main issues that decision-makers face in setting policy related to referral hospitals. Reviews what needs to be done to improve how they function.

Kok, M.C., Dieleman, M., Taegtmeyer, M. et al. 2015. Which intervention design factors influence performance of community health workers in low- and middle-income countries? A systematic review. Health Policy Plan. 30.9:1207-27 *[DOI: 10.1093/heapol/czu126]*

Systematic review of how intervention design affects community health worker performance. Design aspects which can have a positive effect include a mix of financial and non-financial incentives, frequent supervision and continuous training, and embedding community health workers in 
community and health systems. Suggestions for improving performance are clearer definition of roles, and clear processes for communication among different levels of the health system.

Kruk M., Gage A., Arsenault C. 2018. High-quality health systems in the Sustainable Development

Goals era: time for a revolution. Lancet 6: e1196-252 *[doi.org/10.1016/S2214-109X(18)303863]*

Examines the literature, analyses surveys, and reports qualitative and quantitative research which evaluates the quality of care available to people in LMICs. Makes wide-ranging recommendations on how to improve quality, and identifies the benefits.

Lewin, S., Munabi-Babigumira, S., Glenton, C.et al. 2010. Lay health workers in primary and community health care for maternal and child health and the management of infectious diseases. Cochrane Database Syst Rev 3: CD004015.

Systematic review to assess the effects of use of lay health worker (paid or unpaid) in primary and community health care. Finds that lay health workers can promote immunisation uptake and breastfeeding, improve TB treatment outcomes, and reduce child morbidity and mortality, when compared to usual care. There was not enough evidence to draw conclusions about their effects for other health issues.

Mayhew, S.H., Hopkins, J. and Warren, C.E. 2017. Building integrated health systems: lessons from HIV, sexual and reproductive health integration. Health Policy and Plan., 32.suppl_4. iv1iv5. DOI: *[https://doi.org/10.1093/heapol/czx142]*

Introductory and overview paper in a Supplement which explores the health system challenges and successes of delivering integrated services based on studies of HIV, sexual and reproductive health services integration. Papers summarised include reviews, primary data studies and think pieces. Argues that integration efforts need to take a broader systems-wide, people-centred approach if they are to be successful and sustainable.

Schneider, H., Okello, D. and Lehmann, U. 2016. The global pendulum swing towards community health workers in low- and middle-income countries: a scoping review of trends, geographical distribution and programmatic orientations, 2005 to 2014. Hum Resour Health. 14.1:65. *[DOI: 10.1186/s12960-016-0163-2]* 
Examines the growth, geographical distribution and programme orientation of literature on community health workers in low and middle-income countries over a 10-year period. The growth in the literature demonstrates the ever-increasing expectations of community health workers to address health burdens through community-based action. The strong disease- or programme-specific orientation of the literature raises important questions about how these services can be integrated in sustainable national programmes.

\section{The Private Sector}

The role of the private sector in a health system has been the subject of considerable debate and controversy. The very high use of private services, often paid for out-of-pocket, in virtually all low and middle-income countries has been shown by many studies (eg Campbell et al 2016). A Lancet series on 'UHC: markets, profit, and the public good' includes four useful papers, with McPake and Hanson 2016, in the final paper, identifying messages from the papers and drawing on additional sources to inform policy and research agendas in the context of the goal of universal health coverage in lowincome and middle-income countries. A particularly controversial area has been whether a government should outsource health care delivery to the private sector - ie use public funding to contract private service providers (Liu et al 2007), a policy tried in a number of countries. While the greatest emphasis has been on engaging the private sector in the delivery of health services, some countries have also made use of private financing entities. For example, the huge scheme entitled 'Rashtriya Swasthya Bima Yojana' in India involves a public private partnership where private or state enterprise insurers bid to receive a fixed payment per household they enrol in the scheme and organise the provision of hospital care (Virk and Atun 2015), and Chile allowed individuals to opt out of state-managed social health insurance into private insurance schemes which offered access to private services: Roman-Urrestarazu et al 2018 assess the consequences.

\section{Roman-Urrestarazu A., Yang, J.C., Ettelt, C., Thalmann, I., Seguel Ravest, V. and Brayne, C. 2018. Private health insurance in Germany and Chile: two stories of co-existence, segmentation and conflict. International Journal for Equity in Health 17:112 * [DOI: 10.1186/s12939-018-0831- z]*}

Germany and Chile are compared and contrasted since both offer choice between statutory social health insurance and private health insurance. The paper finds that segmentation of insurance markets has had significant consequences for equity, fairness, and financial protection and encouraged private insurers to select for risks, compromising equity in health care funding, increasing the financial risk borne by public insurers, and lowering incentives for efficiency amongst private insurers. 
Campbell, O.M.R., Benova, L., Macleod, D. et al. 2016. Family planning, antenatal and delivery care: cross - sectional survey evidence on levels of coverage and inequalities by public and private sector in 57 low - and middle - income countries. Tropical Medicine \& International Health 21.4:486-503*[DOI: 10.1111/tmi.12681]*

Uses Demographic and Health Surveys for 57 countries from the period 2000-2013 to evaluate the private sector's share in providing family planning, antenatal and delivery care. Finds that the private - sector share in family planning services was 37-39\% across regions, in antenatal care 13$61 \%$, and in deliveries $9-56 \%$. For all three services, women in the richest wealth quintile used private services more than the poorest.

McPake, B. and Hanson, K. 2016. Managing the public-private mix to achieve universal health Coverage. The Lancet 388: 622-30. *[DOI: 10.1016/S0140-6736(16)00344-5]*

Focuses on the public-private mix in the context of universal coverage and draws on the papers in the Lancet series, of which this forms part, to inform policy and research agendas. Explores types of policy appropriate to address four stylised but common private provider types: the low-quality, underqualified sector that serves poor people in many countries; not-for-profit providers; formally registered small-to-medium private practices; and the corporate commercial hospital sector.

Virk A.K. and Atun R. 2015. Towards universal coverage in India: a historical examination of the genesis of Rashtriya Swasthya Bima Yojana - the health insurance scheme for low-income groups. Public Health 129.6.:810-7. *[DOI: 10.1016/j.puhe.2015.02.002.]*

Explores the genesis and early development of Rashtriya Swasthya Bima Yojana, a publicly-funded national health insurance scheme for people below the poverty line. Explains the political drivers for the scheme, and reasons for choice of a health insurance model and management by the private sector.

Liu, X., Hotchkiss, D.R and Bose, S. 2007. The effectiveness of contracting-out primary health care services in developing countries: a review of the evidence. Health Policy and Plan. 23:1-13 *[DOI: $10.1093 /$ heapol/czm042]*

Reviews evidence on the effectiveness of contracting-out and its impact on programme and health systems performance. Finds that contracting-out can improve access to services, but little is known of other effects including equity, quality and efficiency, nor of system-wide effects which could be positive or negative. The context in which contracting-out is implemented and the design features of the interventions are likely to greatly influence the chances of success. 


\section{Universal Coverage}

Universal coverage is a widely shared goal in high income countries, and once which an increasing number of low and middle-income countries aspire to, with some already achieving it. WHO defines universal coverage as 'ensuring that all people have access to needed health services (including prevention, promotion, treatment, rehabilitation and palliation) of sufficient quality to be effective while also ensuring that the use of these services does not expose the user the financial hardship'. It requires the comprehensive structuring of all aspects of a health system. WHO 2010 (see section on *General overviews*) makes the case for universal coverage, with a focus on financing. Country evidence is accumulating on how countries can make progress towards universal coverage and challenges faced (The World Bank, Reich et al 2015). Savedoff et al 2012 describe the historical, political, and economic trends associated with progress toward universal health coverage. Thailand's success in achieving universal health coverage when only a lower-middle-income country has attracted significant attention, and Evans et al 2012 provide an evaluation of Thailand's first 10 years of universal coverage. The cost of universal coverage is a huge challenge in low income countries even given prioritisation of a very basic package of services (Jamison et al 2018), and especially in Africa given low incomes and unstable growth (Russo et al 2017).

\section{Evans, T.G., Chowdhury, A.R., Evans, D.B. et al, 2012, *Thailand's Universal Coverage Scheme: Achievements and Challenges. An independent assessment of the first 10 years (2001-2010). [http://www.jointlearningnetwork.org/uploads/files/resources/book018.pdf] *Nonthaburi, Thailand: Health Insurance System Research Office.}

Reviews the performance of Thailand's universal health coverage scheme to shed light on what worked, what did not work, and why, and to offer policy recommendations to Thailand and lessons for other countries. Examines the policy formulation process, the contextual environment, policy implementation, governance, and impacts including improved access to health services, improved equity of service utilization and medical impoverishment prevented.

\section{Jamison, D., Alwan, A., Mock, C.N. et al. 2017. Universal health coverage and intersectoral action for health: key messages from Disease Control Priorities, $3^{\text {rd }}$ edition. Lancet 391.10125:1108-1120. * [DOI: 10.1016/S0140-6736(17)32906-9.]*}

Uses the analyses from Disease Control Priorities to calculate that full implementation of a highestpriority package of services would cost $\$ 25-45$ (in 2012 dollars) per capita per year on top of what low-income countries are already spending, and would require low-income countries to spend an additional $3 \%$ to $5.5 \%$ of their current gross national income on health care. 
Reich, M.R., Harris, J. Ikegami, N. et al. 2015. Moving towards universal health coverage: lessons from 11 country studies. Lancet, 382.10020:811-816. *[DOI: 10.1016/S0140-6736(15)60002-2]*

Draws together the lessons from a World Bank 11-country study analysing the processes of moving towards universal health coverage. Argues that although universal health coverage is a complex process, it is nonetheless feasible and achievable, requiring both technical solutions and strategies that address the national political economy context.

Russo, G., Bloom, G. and McCoy, D. 2017. Universal health coverage, economic slowdown and system resilience: Africa's policy dilemma. BMJ Globa/2.3. *[DOI: 10.1136/bmjgh-2017000400]*

Argues that African economies face especial challenges in making progress towards universal health coverage given their dependence on commodities whose prices are volatile and the unpredictability of international assistance. Suggests a number of macro, meso and micro policies to strengthen the universal health coverage concept in Africa, and reconcile its aspirations with Africa's current economic outlook.

Savedoff, W.D., de Ferranti, D., Smith, A.L. and Fan, V. 2012. Political and economic aspects of the transition to universal health coverage. Lancet. 380.9845:924-32. *[DOI: 10.1016/S01406736(12)61083-6]*

Reviews and draws lessons from the evidence on how countries have reached universal health coverage. Concludes that the trajectory toward universal health coverage often has three common features: a political process driven by a variety of social forces, growth in incomes and related rise in health spending, and an increase in the share of health spending that is pooled rather than paid outof-pocket by households.

The World Bank. * Going Universal. How countries are implementing pro-poor universal health coverage reforms. Universal Health Coverage Study Series (UNICO).

[http://www.worldbank.org/en/topic/health/publication/universal-health-coverage-studyseries]* Washington DC: World Bank.

Includes the country case studies draw on by Reich et al 2015 plus further ones.

\section{Assessing Health System Performance}

Failings in health systems, including but not only those of low and middle-income countries, have been identified for many years, but the subject of health system performance was first brought to 
world attention by WHO's effort in 2000 to rank all health systems in the world (see WHO 2000 in *General overviews*). The subsequent controversy (McKee 2010) highlighted many challenges, including those of agreeing health system objectives, distinguishing the contribution of the health system relative to other health determinants, selecting indicators, and data availability, and has stimulated further work (Papanicolas et al 2013). Nolte and McKee 2012 provide an overview of issues measuring the performance of health systems. Global assessment based on metrics can shed only some light how and why health systems perform well or badly, and a variety of other approaches are now being offered which offer alternative and complementary methods. Historical studies can add deeper understanding (Balabanova et al 2013); combining survey data with contextual information (Masanja et al 2008) has also been informative; Borghi and Chalabi 2017 argue for greater use of system dynamics and agent-based modelling methods; and Kuruvilla et al 2014 bring a large range of methods together to explore success factors for reducing maternal and child mortality. The 2019 BMJ China collection (BMJ 2019) is one example of the rapidly growing literature evaluating country progress in strengthening health system performance.

Balabanova, D., Mills, A., Conteh, L. et al. 2013. Good Health at Low Cost 25 years on: lessons for the future of health systems strengthening. The Lancet, 381(9833): 2118-33 *[DOI: 10.1016/S0140-6736(12)62000-5]*

Sought to examine why some countries are more successful than others in achieving better health or expanding access to essential services, using historical methods to trace the development of policies and programmes in a set of country case studies. Drew on theories of path dependency and health systems resilience to seek to understand how and why specific developments took place in order to identify plausible pathways to health improvement.

BMJ 2019 China's health system reforms: review of 10 years of progress; $365: 14178$ doi.org/10.1136/bmj.I4178

Evaluates the achievements and challenges of China's 10 year programme of health system reforms, intended to establish an accessible, equitable, affordable, and efficient health system to cover all people by 2020. Identifies the need for ongoing reforms to further extend health system reforms and meet growing health expectations.

Borghi, J. and Chalabi, Z. 2017. Square peg in a round hole: re-thinking our approach to evaluating health system strengthening in low-income and middle-income countries. BMJ Glob Health 2.3:e000406. *[DOI: 10.1136/bmjgh-2017-000406]* 
Argues that conventional evaluation methods ignore the complex and dynamic nature of health systems and that system dynamics and agent-based modelling methods can better reflect the complexity of health systems, be used to estimate value for money for health systems investments and predict health system response to an innovation prior to its introduction.

Masanja, H., de Savigny, D., Smithson, P. et al. 2018. Child survival gains Tanzania: analysis of data from demographic and health surveys. Lancet, 371.9620:1276-1283. *[DOI:

https://doi.org/10.1016/S0140-6736(08)60562-0]*

Sought to answer the question of why mortality in children younger than 5 years had dropped by $24 \%$ between 2000 and 2004 by analysing data from the four demographic and health surveys done in Tanzania since 1990 and investigating contextual factors, within and outside Tanzania's health system, that could have affected child mortality. Was able to convincingly argue that various health system improvements had produced this mortality fall.

Kuruvilla, S., Schweitzer, J., Bishai, D. et al. 2014. Success factors for reducing maternal and child mortality. Bull World Health Organ. 92.7:533-44 *[DOI: 10.2471/BLT.14.138131]*

Summarises the outcome of a multidisciplinary, multi-country series of studies seeking to understand what works to support countries' progress towards the MDGs and to inform the post-2015 goals and strategies. Methods involved quantitative mapping of trends; econometric modelling; Boolean, qualitative comparative analysis; literature review with narrative evidence synthesis; and countryspecific literature and data reviews. The article syntheses the evidence across the five methods using a multi-grounded theory approach.

McKee, M. 2010. The World Health Report 2000: 10 years on. Health Policy and Plan. 25.5: 346$348 *$ [DOI: $10.1093 /$ heapol/czq032]*

Reviews the reactions to the WHO ranking of health system performance and summarises the various criticisms. Argues that nonetheless the ranking was valuable since it placed assessment of health system performance firmly on political and research agendas, provided much needed clarity on the elements of a health system, and stimulated a major programme of research and analysis and the emergence of a research community working on health systems performance.

Nolte, E. and McKee, M. 2012. Measuring and evaluating performance. Pp 49-75 in Smith, R. and Hanson, K. Eds. Health systems in low and middle-income countries. An economic and policy perspective. Oxford: Oxford University Press. 
Examines some of the main conceptual and methodological issues involved in measuring the performance of health systems. Comments on whether and how performance measurement actually makes a difference.

Papanicolas, I., Kringos, D., Klazinga, N.S. and Smith, P.C. 2013. Health system performance comparison: new directions in research and policy. Health Policy. 112.1-2:1-3 *[DOI: 10.1016/j.healthpol.2013.07.018]*

Editorial of a special issue which sets the scene of health system performance comparison and provides an overview of the papers included in the volume which cover the framework used for making comparisons, the performance metrics, analytical techniques used to assure comparability, and drawing policy inferences from comparisons.

\section{Journals}

Health Policy and Planning describes itself as 'the journal on health policy and systems research', and hence has the closest overlap with the topic of health systems with a strong policy orientation. The International Journal of Health Planning and Management has the focus of its title. More recently founded journals are BMC Health Services Research which has been developing a strong global health angle, the International Journal of Health Policy and Management, and the global health publications of the Lancet and BMJ. With the increased interest in global health, other journals, including Health Affairs, at times publish papers relevant to low and middle-income countries. Social Science and Medicine is the leading social science journal, with material relevant to all countries in the world.

\section{*BMC Health Services Research [https://bmchealthservres.biomedcentral.com/]*}

An open access, peer-reviewed journal that considers articles on all aspects of health services research, including delivery of care, management of health services, assessment of healthcare needs, measurement of outcomes, allocation of healthcare resources, evaluation of different health markets and health services organizations, international comparative analysis of health systems, health economics and the impact of health policies and regulations.

\section{*BMJ Global Health [https://gh.bmj.com/]*}

An open access, online journal from BMJ dedicated to publishing high-quality peer-reviewed content relevant to those involved in global health, including policy makers, funders, researchers, clinicians and frontline healthcare workers. Seeks to address the information problem in global health by being an open and inclusive discussion forum that brings together and addresses the broad community of 
global health stakeholders.

\section{*Health Affairs [https://www.healthaffairs.org/]*}

A multidisciplinary, peer-reviewed journal dedicated to the serious exploration of major domestic and international health policy issues, especially those that are of concern to and engage both the private and the public sectors.

\section{*Health Policy and Planning [https://academic.oup.com/heapol]*}

Publishes health policy and systems research focusing on low- and middle-income countries and provides an international forum for original and high-quality research that addresses questions pertinent to policy-makers, public health researchers and practitioners.

\section{*International Journal of Health Planning and Management [https://onlinelibrary.wiley.com/journal/10991751]*}

Offers a forum for publications which direct attention to major issues in health policy, planning and management; aims to maintain a balance between theory and practice, from a variety of disciplines, fields and perspectives.

\section{*International Journal of Health Policy and Management [http://www.ijhpm.com/]*}

An open access, peer-reviewed journal which serves as an international and interdisciplinary setting for the dissemination of health policy and management research, bringing together fields such as health management/policy/economics, epidemiology, social/public policy, and philosophy.

\section{*The Lancet Global Health [https://www.thelancet.com/journals/langlo/issue/current]*}

Focuses on disadvantaged populations wherever they are, with a preference for topics which are mainly disease or programme specific but which include the global health workforce, health systems, and health policy.

\section{*Social Science and Medicine [https://www.journals.elsevier.com/social-science-and- medicine]*}

Provides an international and interdisciplinary forum for the dissemination of social science research on health, publishing original research articles (both empirical and theoretical), reviews, position papers and commentaries on health issues, to inform current research. 


\section{Data Sources}

Data relevant to health systems can be obtained from many websites. WHO, the World Bank, and UNICEF all offer data resources relevant to their missions. OECD holds the Development Advisory Committee (DAC) database on official development assistance (ODA). The European Observatory on Health Systems and Policies has resources on the health systems of the countries in its respective region, a number of which are not high-income countries.

\section{*European Observatory on Health Systems and Policies [http://www.euro.who.int/en/about- us/partners/observatory]*}

The Health Systems and Policy Monitor page provides detailed information on countries in the region (https://www.hspm.org/mainpage.aspx). The Health System Reviews page provides access to the Health System in Transition reports (HiTs) (http://www.euro.who.int/en/aboutus/partners/observatory/publications/health-system-reviews-hits).

*The Institute of Health Metrics and Evaluation (IHME) [http://www.healthdata.org/policyreport/financing-global-health-2017]*

Does an annual policy report on financing global health; text available on the website plus a variety of other resources including data visualisations.

*OECD Development Finance data [http://www.oecd.org/dac/financing-sustainabledevelopment/development-finance-data/]*

Holds the database on development finance which can be used to analyse development finance for health.

\section{*World Health Organization Global Health Observatory}

[http://apps.who.int/gho/data/node.resources]*

Provides health related statistics for all 194 member countries. Each WHO Regional office website also has health-related statistics relating to the countries in each region.

*World Bank DataBank [http://databank.worldbank.org/data/home.aspx]*

Provides access to World Bank data on a variety of topics including health. 
*UNICEF [https://data.unicef.org/]*

Provides access to UNICEF's data.

\section{Toolkits For Health Systems Assessment}

There are various toolkits available to help countries assess specific dimensions of their health system. WHO provides a toolkit for monitoring the health system building blocks. Toolkits for assessing service availability and readiness (SARA) and service provision (SPA) focus on the service delivery level.

*WHO health systems assessment toolkit, Monitoring the building blocks of health systems: a handbook of indicators and their measurement strategies.

[http://www.who.int/healthinfo/statistics/toolkit_hss/en/index.html]*

Describes a set of indicators and related measurement strategies.

*Service Availability and Readiness Assessment (SARA) . World Health Organization. [http://www.who.int/healthinfo/systems/SARA_Reference_Manual_Full.pdf]*

Provides an annual monitoring system for service delivery.

*Service Provision Assessment (SPA) Surveys

[https://dhsprogram.com/pubs/pdf/OF25/OF25.pdf]*

Provides a health facility assessment tool that provides a comprehensive overview of a country's health service delivery.

\section{Other Online Resources And Websites}

Many organizations, initiatives, projects and programmes have websites with useful resources. Health Systems Global is a membership organization for those engaged in health systems research and policy. The Alliance for Health Policy and Systems Research was set up to encourage research and capacity building in this field. IHP news is a useful weekly newsletter with topical news and publications all highly relevant to health systems. Cochrane EPOC provides systematic reviews of health systems/services issues, and the Health Systems Evidence site provides access to health systems evidence. A number of websites offer resources specially relating to universal health coverage, notably the Joint Learning Network, and UHC 2030. Major projects and programmes offer resources too numerous to be mentioned here, but they can be found via web searches on health system themes. 


\section{*Alliance for Health Policy and Systems Research [http://www.who.int/alliance-hpsr/en/]*}

Mission is to promote the generation and use of health policy and systems research (HPSR) as a means to strengthen the health systems of low-and middle-income countries.

\section{${ }^{*}$ Cochrane Effective Practice and Organization of Care (EPOC) [https://epoc.cochrane.org/]*}

Undertakes and publishes systematic reviews of educational, behavioural, financial, regulatory and organizational interventions designed to improve health professional practice and the organisation of health care services.

\section{*Health Systems Global [http://www.healthsystemsglobal.org/]*}

Convenes researchers, policy-makers and implementers from around the world to develop the field of health systems research and create, share and apply knowledge to strengthen health systems. Holds a biennial symposium.

\section{*IHP news [http://www.internationalhealthpolicies.org/]*}

Publishes a weekly online newsletter which has a focus on health policy and systems issues.

\section{*Joint Learning Network for Universal Health Coverage \\ [http://www.jointlearningnetwork.org/]*}

Network of practitioners and policymakers from around the world who co-develop global knowledge products that help bridge the gap between theory and practice in universal health coverage.

\section{*Health Systems Evidence [https://www.healthsystemsevidence.org/]*}

Continuously updated repository of syntheses of research evidence about governance, financial and delivery arrangements within health systems, and about implementation strategies that can support change in health systems

\section{*UHC 2030 [https://www.uhc2030.org/]*}

Provides multi-stakeholder platform to promote collaborative working in countries and globally on health systems strengthening. 
